\title{
Every picture tells a story: Content analysis of medical school website and prospectus images in the United Kingdom
}

\author{
Jack Macarthur · Mike Eaton · Karen Mattick
}

Published online: 25 July 2019

(c) The Author(s) 2019

\begin{abstract}
Introduction The decision-making process for students as to which medical schools to apply to is open to many factors and influences. Research has identified several factors which influence prospective students' choice of medical school and career. There is also evidence that websites and prospectuses may be creating potential barriers to widening access.

Methods The websites and prospectuses of 33 medical schools in the United Kingdom were searched for relevant images. These images and the people in them were subjected to inclusion/exclusion criteria. Data about the images and people were recorded so that a content analysis could be performed. The relative proportions were compared with pre-existing data relating to the medical profession and society.

Results From 33 medical schools, 650 images were included, with 1,817 people depicted. The largest group for the assumed roles was 'student', as expected, with 1,423 people $(78 \%)$. For the overall theme of the image, community placement themed images made up only $2 \%$ of images (14) and hospital placement themed images made up 24\% (154). Chi-squared goodness of fit showed statistically significant results for most groups of data when comparing ethnicity, the overall theme of the image and assumed specialty group, but not when comparing gender.

Discussion In conclusion, for gender, medical schools are accurately reflecting national data. However, for ethnicity medical schools fail to accurately represent
\end{abstract}

J. Macarthur $(\bowtie) \cdot$ M. Eaton $\cdot$ K. Mattick

College of Medicine \& Health, University of Exeter,

Exeter, UK

jackmacarthur1@outlook.com

\section{K. Mattick}

Centre for Research in Professional Learning, University of Exeter, Exeter, UK national data, leading to incorrect signalling about the ethnic makeup of their students. Additionally, medical schools are signalling to students a strong preference for hospital-based settings, despite a strong national drive to recruit more general practitioners.

Keywords Medical education · Images . Prospectuses · Websites

\section{Introduction}

Ensuring the right number and 'type' of medical students enter undergraduate training is an important and challenging task. In the United Kingdom (UK) the number of medical students is carefully governed by the Department of Health. In August 2017, the Department of Health announced an increase in the number of places for medical students by 1,500 [1], an increase of $25 \%$ from the previous 6,000 places [2]. The allocation of these additional places was determined by several different elements [3] but preference was given to medical schools that showed their recruitment strategy created a future workforce reflecting the

\section{What this paper adds}

Choosing the 'right' students to admit to medical school is critically important. Research has shown that medical schools can influence why people apply to medicine and the specialty they chose. Images are one of the ways that medical schools convey information about themselves and the medical profession to students. This paper adds value to the existing literature by evaluating the images chosen by medical schools for their websites and considering how these might inadvertently affect the choices made by prospective students. 
population it served [1]. Furthermore, curricula with a greater proportion of general practice placements were favoured since greater recruitment to this specialty is needed and longitudinal placements within general practice have been reported to positively influence medical students' choice of general practice as their future career [4]. However, it remains to be seen whether this strategy will prove successful in creating a more diverse pool of graduates who are more likely to choose general practice.

To achieve a more diverse workforce in the right specialty areas, we need to understand more about how applicants to medical school make their decisions and how they choose a specialty. There is little large-scale research to date exploring how potential applicants choose a medical school. Foster identified five areas influencing their choice [5]: curriculum factors, the reputation of the school, personal contact, location, and facilities. Similarly, Brown stated three factors influenced prospective students' choice: academic factors, location factors, and 'intangibles' [6]. The first point of contact was usually the medical school website or prospectus, and both studies highlight the importance of an impression formed about a place, for example, based on images, anecdotes, and individual experiences, rather than the more logical-rational decision making one might have anticipated. This is consistent with research done by Cleland et al. [7] which also showed medical schools influenced medical students' future career choices.

A study by McHarg et al. [8] showed how important having a supportive figure is in applying to medical school, with several students reporting that without the support of someone else they would not have applied. As such it is important that the images used do not create barriers by undermining crucial support.

A study by Chowdhury et al. [9] reviewed images used in prospectuses by medical schools to determine the frequency different learning environments were shown. They found that $46 \%$ of prospectuses had images of students in laboratories, $41 \%$ had images of students in clinical skills settings, $34 \%$ of prospectuses had images of students in a hospital setting and only $6 \%$ had images of students in community settings. Alexander et al. [10] showed that websites may be creating a barrier to widening access to medicine through the language that they use. As such it is important to see if the images used on websites are also creating potential barriers as well.

Visual cues are increasingly known to be important influencers of choice in a range of fields [11, 12]. This makes sense considering theories such as signalling theory [13], image theory [14, 15], and social identity theory [16]. Signalling theory states that one party communicates information about itself to another party via signals. The receiver uses the signals to determine the credibility and suitability of the sender. Image theory deals with how objects are assessed to determine the compatibility with the indi- vidual's values and ethics. Compatibility is primarily based upon any violations of compatibility; violations are not compensated for by positive attributes. Social identity theory states people align themselves with a group whom they consider to have similar characteristics to themselves.

It is likely that images on websites and in prospectuses are important influencers of medical school and specialty choice, and as such important in shaping the future workforce. However, we do not know whether these images are aligned with national recruitment priorities and it is possible that website images are undermining efforts to widen access to medicine.

This article aims to answer the research question: to what extent do the images of people used within UK medical school prospectuses and websites reflect current demographic data for medical students and healthcare professionals?

\section{Methodology}

\section{Study design}

This research involves a content analysis of the photographic images embedded within medical school websites and prospectuses. Haggarty defines content analysis as 'a research method which allows the qualitative data collected in research to be analyzed systematically and reliably so that generalizations can be made from them in relation to the categories of interest to the researcher' [17].

\section{Medical schools}

The UK Medical School Council website was used to compile a list of UK medical schools [18]. To be included, medical schools had to offer an accredited medical degree with either undergraduate or postgraduate entry and be actively recruiting students. The 33 medical schools were each assigned a number using a random number generator, to protect their identities. For each medical school, the website and prospectus were searched to locate images suitable for this research.

\section{Image bank}

For image collection from websites, only webpages related to the medical course and from the medical school home page were included, all other university or medical school webpages were excluded. For images from prospectuses, the pages included were the title page, any pages up to and including the contents, and pages specifically relating to the medical degree; all other pages were excluded.

The inclusion criteria for images taken from the included webpages/prospectus pages were: the image includes at least one person, and the image is related to the medical degree program. Images were 
excluded from collection if they were from news articles; about the student experience not related to the medical course or contained more than 15 people.

\section{Data extraction}

Data from the images were extracted and entered into a Microsoft Excel database. For each person in each image, the following information was recorded: assumed role (e.g. student, teacher, doctor, patient, nurse, other); assumed sex; assumed ethnicity category; and assumed age category. For each image, the following information was recorded: the total number of people; total number for each assumed role; and overall theme (academic, community placement, hospital placement, and other). If two or more data points could not be recorded about an individual, then that individual was excluded. Where the assumed role of a person in an image was a doctor, they were further categorized as to their assumed specialty group (community-based or hospital-based). In the database, the UK country (England or other UK country) and research status (research intensive or non-research intensive) were also recorded for the medical school. Research-intensive universities were defined as those that were members of the 'Russell group', which defines itself as 'a group of leading UK universities who are committed to maintaining high quality research along with an exceptional learning and teaching experience'.

The data were extracted by JM with $10 \%$ of the images (selected at random) reviewed by a second researcher (ME or KM). Any differences of opinion were resolved through discussion, involving the third author where necessary.

\section{Comparator data}

Comparator data were identified against which to compare the image bank. Demographic data were obtained about the UK public from the Office of $\mathrm{Na}$ tional Statistics using the latest census [19]. National Health Service (NHS) Digital was used to collect demographic data for doctors and nurses [20]. The General Medical Council Medical School Annual Return was used to gather demographic data for medical students [21]. The Russell Group website was used to ascertain the Russell Group status for each medical school [22]. Demographic data for teachers were obtained from the Higher Education Statistics Agency [23]. Where there was not a specific comparator data group, UK census data were used [19].

\section{Data analysis}

Descriptive statistics were calculated for each category. Chi-squared goodness of fit test was used to compare the image bank to the comparator data, since the data were categorical, and aimed to com- pare observed frequencies and expected frequencies. For comparison using the chi-squared goodness of fit, for ethnicity, the categories of other, mixed, and unknown were combined into one group. If the group had a value of 0 , then a value of 1 was assigned. For the results of the chi-squared goodness of fit, the cut off for rejecting or accepting the null hypothesis was set at $p<0.05$ for statistical significance. Statistical analysis was conducted using IBM SPSS 24. The database was also analyzed by different groupings of medical school: research intensive and non-research intensive; and by UK region: England and other UK countries.

\section{Hypotheses}

Four null hypotheses guided the data analysis, as follows:

1. There will be no significant differences in the proportion of females and males in the images identified and the comparator data.

2. There will be no significant differences in how ethnicity is represented in the images identified and the comparator data.

3. The proportion of the overall themes of the images will be equal.

4. The proportions of the two groups of assumed specialties will be equal.

\section{Research ethics}

Ethical approval was obtained from the MSc Clinical Education program team, operating with delegated authority on behalf of the University of Exeter Medical School's Research Ethics Committee.

\section{Results}

\section{Description of images}

A total of 650 images, including 1,817 people, met the inclusion criteria. The median number of images per medical school was 19 , with a median number of 2 people per image. Twenty medical schools were identified as being research intensive and 13 were not; 25 were identified as being in England and 8 in other UK countries.

Table 1 provides data relating to the assumed role of people in the images. Of the people in the images, $78 \%$ were assumed to be students $(n=1,423), 6 \%$ doctors $(n=108), 6 \%$ teachers $(n=100), 4 \%$ patients $(n=70)$, $2 \%$ nurses $(n=37)$ and $4 \%$ had 'other roles' $(n=79)$.

Table 2 provides data relating to the setting of the images. Only 2\% of the images (14/650) portrayed a community setting, whereas $24 \%$ (154/650) depicted a hospital setting and $40 \%$ of the images had another setting. Similarly, only $9 \%$ of the doctors $(10 / 108)$ portrayed a community-based specialty, and 
Table 1 Data on assumed roles and image information

\begin{tabular}{|c|c|c|c|c|c|c|c|c|}
\hline Data group & Image & People & Student & Teacher & Doctor & Patient & Nurse & Other \\
\hline Entire dataset (\%) & $650(100)$ & $1817(100)$ & $1423(78)$ & $100(6)$ & $108(6)$ & $70(4)$ & $37(2)$ & $79(4)$ \\
\hline Research intensive (\%) & $384(59)$ & $1083(60)$ & $879(81)$ & $60(6)$ & $57(5)$ & $35(3)$ & $18(2)$ & $34(3)$ \\
\hline Non-research intensive (\%) & $266(41)$ & $734(40)$ & $544(74)$ & $40(5)$ & $51(7)$ & $35(5)$ & $19(3)$ & $45(6)$ \\
\hline England (\%) & $511(79)$ & $1421(78)$ & $1110(78)$ & $74(5)$ & $90(6)$ & $52(4)$ & $30(2)$ & $65(5)$ \\
\hline Other UK countries (\%) & $139(21)$ & $396(22)$ & $313(76)$ & $26(8)$ & $18(5)$ & $18(5)$ & $7(2)$ & $14(4)$ \\
\hline
\end{tabular}

Table 2 Data on overall theme of the image and the assumed specialty group of the portrayed doctors

\begin{tabular}{|c|c|c|c|c|c|c|}
\hline Data Group & Academic & Community & Hospital & Other & Community-based doctor & Hospital-based doctor \\
\hline Entire dataset (\%) & $223(34)$ & $14(2)$ & $154(24)$ & $259(40)$ & $10(9)$ & $98(91)$ \\
\hline Research intensive (\%) & $142(37)$ & $6(2)$ & $81(21)$ & $155(40)$ & $6(11)$ & $51(89)$ \\
\hline Non-research intensive (\%) & $81(30)$ & $8(3)$ & $73(27)$ & $104(39)$ & $4(8)$ & $47(92)$ \\
\hline England (\%) & $179(35)$ & $13(3)$ & $117(23)$ & $202(40)$ & $9(10)$ & $81(90)$ \\
\hline Other UK countries (\%) & $44(31)$ & $1(0)$ & $37(26)$ & $57(43)$ & $1(6)$ & 17 (94) \\
\hline
\end{tabular}

Table 3 Data for assumed gender and assumed ethnicity

\begin{tabular}{|c|c|c|c|c|c|c|}
\hline Data group & Female & Male & Asian & Black & White & Other \\
\hline Entire dataset (\%) & $1025(56)$ & $792(44)$ & 401 (22) & $88(5)$ & $1328(73)$ & $0(0)$ \\
\hline Student (\%) & $823(58)$ & $600(42)$ & $364(26)$ & $74(5)$ & $985(69)$ & $0(0)$ \\
\hline Teacher (\%) & $36(36)$ & $64(64)$ & $13(13)$ & $2(2)$ & $85(85)$ & $0(0)$ \\
\hline Doctor (\%) & $41(38)$ & $67(62)$ & $15(14)$ & $4(4)$ & $89(82)$ & 0 \\
\hline Patient (\%) & $34(49)$ & $36(51)$ & $2(3)$ & $1(1)$ & $67(96)$ & $0(0)$ \\
\hline Nurse (\%) & $36(97)$ & $1(3)$ & $2(5)$ & $5(14)$ & $30(81)$ & $0(0)$ \\
\hline
\end{tabular}

91\% (98/108) portrayed a hospital-based specialty. These trends were consistent across groups (Tab. 2).

Table 3 provides data relating to the ethnicity and gender of the people in the images. The largest ethnic group category portrayed was 'White/White British', accounting for $73 \%$ of people $(n=1,328)$, followed by $22 \%$ 'Asian/Asian British' $(n=401)$ and 5\% 'Black/ Black British' ( $n=88$ ). Whilst the percentages fluctuated slightly across the different assumed roles and groups of data the order stayed the same, apart from people who were assumed to be nurses, where there was a larger proportion of people who were assumed to be 'Black/Black British' (14\%) than people who were assumed to be 'Asian/Asian British' (5\%).

\section{Hypothesis 1-Assumed gender}

The first null hypothesis was accepted for all but two groups of data (Tab. 4), i.e. the proportions of male to female gender for people in the images is approximately as you would expect based on national data amongst students, doctors, patients, and teachers. The proportions of male to female gender was significantly different to that expected in the images of nurses and 'other', although the numbers are small. Additionally, the null hypothesis was accepted for all the subgroups for the assumed role of students (i.e. the images appropriately represent the proportions of male to female gender amongst medical students).

\section{Hypothesis 2-Assumed ethnicity}

The second null hypothesis was rejected for students, doctors, teachers, nurses, but accepted for patients and 'other' (Tab. 4). The proportions of the ethnicity of people represented in the images were not as expected for all healthcare professionals and students. Further analysis by medical school subgroups suggested that no group of medical schools was accurately representing the proportions expected for ethnicity.

\section{Hypothesis 3-Assumed setting}

The third null hypothesis was rejected across the board. Community settings were significantly underrepresented in the images portrayed, compared with hospital settings and/or academic settings (Tab. 4).

\section{Hypothesis 4-Assumed specialty group}

The fourth null hypothesis was also rejected across the board (Tab. 4). Community specialists were significantly underrepresented in the images portrayed, compared with hospital specialists (Tab. 4). Of the 108 people who were assumed to be a doctor, only 10 of them were assumed to have a community-based specialty. Statistics from NHS Digital regarding fulltime equivalents for general practitioners (GPs) and hospital consultants, show GPs make up 41.95\%, and hospital consultants make up $58.05 \%$ of senior doc- 
Table 4 Results for chi squared goodness of fit

\begin{tabular}{|c|c|c|c|c|c|}
\hline Data for & Observed Frequency & Expected frequency & Chi squared & Degree of freedom & $P$ value \\
\hline \multirow[t]{15}{*}{ Sex } & Entire dataset & Census & 1.045 & 1 & 0.307 \\
\hline & Research intensive & Census & 1.276 & 1 & 0.259 \\
\hline & Non-research intensive & Census & 0.676 & 1 & 0.411 \\
\hline & England & Census & 1.000 & 1 & 0.317 \\
\hline & Other UK countries & Census & 2.632 & 1 & 0.105 \\
\hline & Doctor & NHS & 2.151 & 1 & 0.143 \\
\hline & Other roles & Census & 14.612 & 1 & $<0.001$ \\
\hline & Patient & Census & 0.143 & 1 & 0.705 \\
\hline & Nurse & NHS & 6.839 & 1 & 0.009 \\
\hline & Teacher & HESA & 3.792 & 1 & 0.052 \\
\hline & Student & GMC & 0.514 & 1 & 0.473 \\
\hline & Student—research intensive & GMC & 0.842 & 1 & 0.359 \\
\hline & Student-non-research intensive & GMC & 0.099 & 1 & 0.753 \\
\hline & Student—England & GMC & 0.362 & 1 & 0.547 \\
\hline & Student—other UK countries & GMC & 1.251 & 1 & 0.263 \\
\hline \multirow[t]{15}{*}{ Ethnicity } & Entire dataset & Census & 37.343 & 3 & $<0.001$ \\
\hline & Research intensive & Census & 36.052 & 3 & $<0.001$ \\
\hline & Non-research intensive & Census & 39.314 & 3 & $<0.001$ \\
\hline & England & Census & 24.676 & 3 & $<0.001$ \\
\hline & Other UK countries & Census & 51.949 & 3 & $<0.001$ \\
\hline & Doctor & NHS & 35.646 & 3 & $<0.001$ \\
\hline & Other roles & Census & 1.510 & 3 & 0.680 \\
\hline & Patient & Census & 5.636 & 3 & 0.131 \\
\hline & Nurse & NHS & 14.031 & 3 & 0.003 \\
\hline & Teacher & HESA & 12.910 & 3 & 0.005 \\
\hline & Student & GMC & 12.378 & 3 & 0.006 \\
\hline & Student—research intensive & GMC & 12.364 & 3 & 0.006 \\
\hline & Student—non-research intensive & GMC & 14.921 & 3 & 0.002 \\
\hline & Student-England & GMC & 13.161 & 3 & 0.004 \\
\hline & Student—other UK countries & GMC & 11.886 & 3 & 0.008 \\
\hline \multirow[t]{5}{*}{ Theme } & Entire dataset & Equal & 33.440 & 3 & $<0.001$ \\
\hline & Research intensive & Equal & 36.560 & 3 & $<0.001$ \\
\hline & Non-research intensive & Equal & 28.636 & 3 & $<0.001$ \\
\hline & England & Equal & 32.188 & 3 & $<0.001$ \\
\hline & Other UK countries & Equal & 37.099 & 3 & $<0.001$ \\
\hline \multirow[t]{5}{*}{ Speciality } & Entire dataset & Equal & 67.240 & 1 & $<0.001$ \\
\hline & Research intensive & Equal & 70.560 & 1 & $<0.001$ \\
\hline & Non-research intensive & Equal & 60.840 & 1 & $<0.001$ \\
\hline & England & Equal & 64.000 & 1 & \\
\hline & Other UK countries & Equal & 72.516 & 1 & $<0.001$ \\
\hline
\end{tabular}

NHS National Health Service Digital, HESA Higher Education Statistics Agency, GMC General Medical Council

tors, meaning the percentages shown in this research of $9.26 \%$ for community-based doctors and $90.74 \%$ for hospital doctors fall significantly short of the comparator data [24].

\section{Discussion}

This research set out to answer the question 'To what extent do the images of people used within UK medical school prospectuses and websites reflect current demographic data for medical students and healthcare professionals?'. A large dataset of 650 images portraying 1,817 people was compiled and analyzed against comparator data. This research adds value to the existing literature by evaluating the impact of images medical schools use, and how these might be affecting personal contact factors identified by Foster [5] and the intangible factors identified by Brown [6]. It also builds upon research done by Chowdhury et al. 
into the types of learning environments displayed by medical schools [9].

Our analysis showed the proportion of female to male people in the images was appropriately represented, alleviating concern about potential barriers to women joining the medical profession. While the factors involved with making such decisions are complex and poorly understood, it is imperative that gender is accurately represented in the images used to attract prospective students so as to avoid any potential discrimination or creation of barriers.

However, the proportions of different ethnicities were substantially different to that which would be expected based on the comparator data for medical students, doctors, nurses, and teachers. This implies that generally ethnicity is poorly reflected by the images used. Applying image theory, the photos have a significant potential to be negatively influencing peoples' decision making by violating fundamental values around diversity and equality. Framing this finding in the context of social identity theory, the images used could be posing a barrier for people from ethnic minority groups from applying to medical school, as the images do not show it to be as ethnically diverse as would be expected. Considering the impact images have on decision making and perceptions, having official images showing a less ethnically diverse group of people than the comparator data shows, undermines widening access to medicine. It is possible that potential medical students who would make excellent doctors are put off before they even apply for a place at medical school.

Given the challenges in recruiting to general practice in the UK, the underrepresentation of community settings and specialties in the images we analyzed is surprising. The key role of community placements in medical education appears to be significantly underplayed in the images chosen, which may serve to undermine the recent initiatives by regulatory bodies and universities. Research by Chowdhury et al. analyzed the use of images in prospectuses for the depiction of different learning environments; they found similarly low proportions of UK medical schools representing community placements as a place of learning, with only 2 of the 32 prospectuses depicting community placements [9]. This shows the underrepresentation of community placements is not a new phenomenon but unfortunately has not changed in the last 9 years. This builds on the signals medical schools are sending with the overall theme of the image, and image theory suggests that this longstanding preference for hospital-based images may be putting off potential students from choosing general practice as their specialty.

It is interesting to reflect upon why there was under-representation in the images used on medical school websites. Although our research was not designed to capture these reasons, we suspect they result from subtle unconscious bias when selecting images, perhaps based on nothing more sinister than judgements about what will make for a 'good' or 'interesting' or 'exciting' photograph. Images portraying fast moving and high technology hospital placements may be thought to be more visually appealing for a photograph than community placements, for example. However, the impact of these judgements is far-reaching and we suggest they should be made by those with in depth knowledge of the relative proportions outlined in this research.

\section{Strengths and Limitations}

A strength of this study is the large dataset collected and analyzed, comprising 650 images and 1,817 people. Another strength is that the data analysis was hypothesis-led, leading to a more rigorous approach to interpreting the results. A limitation of the research is that most data extraction was undertaken by a single researcher, with only $10 \%$ verified by a second researcher, and thus prone to subtle biases and influences. Similarly, the data that could be collected, for example on ethnicity, were relatively crude. Another limitation of this study is that the number of webpages and images which were excluded was not recorded due to the limited resources available for the project. As this study only included images from UK medical schools it is important to be cautious about generalizing the findings to other country settings, further research internationally would be valuable to ascertain if these findings are generalizable.

\section{Implications for policy and practice}

It is important that medical schools update the images displayed on their websites and in their prospectuses, to accurately portray the diverse applicants they aspire to recruit and to portray the range of career choices available to these applicants through the images they choose.

We suggest that medical schools worldwide examine and evaluate their websites, prospectuses, and other promotional material for implicit messages they may be sending, which may support or undermine the rhetoric of widening access to medicine and the subsequent messages about the medical workforce they would like to create.

To ensure that there are sufficient drivers and accountability for medical schools to enact this change, key stakeholders such as regulatory or licencing bodies, should be involved to ensure the issues highlighted are dealt with moving forward.

To build on this study, qualitative research with potential applicants to medical school would be helpful to ascertain the extent these images have on influencing applicants' choices. Additionally, alignment of promotional images could be evaluated by monitoring for any changes in applicants and by reviewing 
current student career intentions and graduate destinations.

Whilst this research has focussed on UK medical schools, the importance and benefits of a multicultural and diverse medical workforce are not limited to the UK. Thus, we suggest that the findings and recommendations of this research are likely to be transferrable to other country settings, although future research beyond the UK with similar study designs will be needed to confirm this.

\section{Conclusion}

In conclusion, this research has found that, while the images used by medical schools are representative of the expected proportions for gender, they are not representative of ethnicity, and this should be addressed. Additionally, the number of images which show community placements or communitybased doctors is much lower than those of hospital placements or hospital-based doctors. By altering the proportion of community themed images, it may be possible to attract prospective students for whom this represents the career path they want. At the very least it sets the expectation early that a substantial proportion of medical students will become GPs, so the medical workforce can meet the challenges of the future. Medical schools should consider signalling theory, image theory and social identity theory as well as their potent impacts on students' decision making when selecting images to display on their websites or prospectuses.

Conflict of interest J. Macarthur, M. Eaton and K. Mattick declare that they have no competing interests.

Open Access This article is distributed under the terms of the Creative Commons Attribution 4.0 International License (http://creativecommons.org/licenses/by/4.0/), which permits unrestricted use, distribution, and reproduction in any medium, provided you give appropriate credit to the original author(s) and the source, provide a link to the Creative Commons license, and indicate if changes were made.

\section{References}

1. Department of Health. Expansion of undergraduate medical education-government response to consultation 2017. 2018. https://www.gov.uk/government/consultations/ expanding-undergraduate-medical-education. Accessed 12 Jan 2018.

2. Roberts N, Bolton P. Medical school places in england from September (2018)-briefing paper: the house of common library. 2018. http://researchbriefings.parliament.uk/ ResearchBriefing/Summary/CBP-7914 (Created 29 Mar 2017). Accessed 14Jan 2018

3. Health Education England. New medical schools to open to train doctors of the future: Health Education England.
2018. https://hee.nhs.uk/news-blogs-events/news/newmedical-schools-open-train-doctors-future. Accessed 14 May 2018.

4. Amin M, Chande S, Park S, Rosenthal J, Jones M. Do primary care placements influence career choice: what is the evidence? Educ Prim Care. 2018;29:64-7.

5. Foster K. Medical school choice: what influences applicants? Clin Teach. 2014;11:307:10.

6. Brown C. A qualitative study of medical school choice in the UK. Med Teach. 2007;29:27-32.

7. Cleland JA, Johnston PW, Anthony M, Khan N, Scott NW. A survey of factors influencing career preference in newentrant and exiting medical students from four UK medical schools. Bmc Med Educ. 2014;14(1):151.

8. McHargJ, MattickK, KnightLV.Whypeopleapply to medical school: implications for widening participation activities. MedEduc. 2007;41:815-21.

9. Chowdhury S, Chowdhury R, Sandars J. A picture is worth a thousand words: the use of visual imagery in medical school application prospectuses in the UK. Med Teach. 2009;31:463-4.

10. Alexander K, Fahey PT, Nicholson S, Cleland J. 'Why not you?' Discourses of widening access on UK medical school websites. MedEduc. 2017;51:598-611.

11. Visual Imagery RJ. Applications to advertising. Adv Consum Res. 1982;09:101-6.

12. Pike S. Destination image analysis-a review of 142 papers from 1973 to 2000. Tour Manag. 2002;23:541-9.

13. Spence M. Job market signaling. Quart J Econ. 1973;87:355-74.

14. Beach LR. Image theory: decision making in personal and organizational contexts. Chichester: Wiley; 1990.

15. Beach LR. Image theory: an alternative to normative decision theory. Adv Consum Res. 1993;20:235-8.

16. Tajfel H. Social identity and intergroup behaviour. Soc Sci Inform. 1974;13:65:93.

17. Haggarty L. What is content analysis? Med Teach. 1996;18:99-101.

18. Medical Schools Council. Medical schools: MedicalSchools Counci. 2017. https://www.medschools.ac.uk/studyingmedicine/medical-schools. Accessed 12 Dec 2017.

19. Office for National Statistics. UK census. 2011. https:// www.ons.gov.uk/census/2011census/2011censusdata/ 2011censusdatacatalogue. Accessed 22 April 2018.

20. NHSDigital. Staffbystaffgroup, grade, genderandethnicity. 2017. https://digital.nhs.uk/data-and-information/finddata-and-publications/supplementary-information/ 2018-supplementary-information-files/staff-by-staffgroup-grade-gender-and-ethnicity-september (Created 09.2017). Accessed 25 June 2018.

21. General Medical Council. Medical school annual return 2016-17.. https://www.gmc-uk.org/education/reportsand-reviews/medical-school-reports. Accessed 14 Jan 2018.

22. Russell Group. Russell group website. 2018. https:// russellgroup.ac.uk/. Accessed 13 Jan 2018.

23. Higher Education Statistics Agency. Data and analysis-staff. 2018. https://www.hesa.ac.uk/data-andanalysis/staff. Accessed 25 June 2018.

24. NHS Digital. Statistics show change in NHS workforce over time. 2018. https://digital.nhs.uk/news-and-events/ latest-news/statistics-show- change-in-nhs-workforceover-time. Accessed 12 Jan 2018. 